\title{
Factors influencing the effectiveness of recombinant human soluble thrombomodulin on disseminated intravascular coagulation: a retrospective study
}

\author{
Yuki Asai, , Takanori Yamamoto, Daisuke Kito, Kazuya Ichikawa and Yasuharu Abe
}

\begin{abstract}
Background: Although recombinant human soluble thrombomodulin (rTM) has been widely used to treat disseminated intravascular coagulation (DIC) in Japan, there is no consensus regarding rTM efficacy. Therefore, if the factors influencing rTM efficacy is revealed, it may be possible to demonstrate the effectiveness of rTM by limiting the patients who use rTM. This study investigated the factors of rTM treatment which influence DIC status.

Methods: This retrospective case-control study enrolled hospitalized adult patients treated with rTM from October 2010 to May 2020. Among these patients, 227 who were diagnosed with DIC according to the Japanese Association for Acute Medicine DIC scoring system were assessed. The primary endpoint was the 28-day mortality after rTM treatment. For Cox-proportional hazards model, explanatory factors determined using univariate analysis with $p<0.1$ were used. In addition, some factors considered to affect DIC-related mortality such as age $\geq 75$ years, rTM dose $\geq 380 \mathrm{U} / \mathrm{kg}$, antithrombin III treatment, and diseases with a poor prognosis (sepsis, solid tumors, and trauma) were added as covariates.
\end{abstract}

Results: Univariate analyses suggested that male sex $(p=0.029)$, treatment in intensive care unit $(p=0.061)$, and prothrombin time-international normalized ratio (PT-INR) $(p<0.001)$ were the factors influencing DIC-related 28-day mortality after $r$ TM treatment. According to Cox-proportional hazard analysis, the adjusted odds ratio for DIC-related 28-day mortality in patients with PT-INR $\geq 1.67$ was 2.23 (95\% confidence interval: $1.451-3.433, p<0.001$ ), age $\geq 75$ years was 1.57 (95\% confidence interval: 1.009-2.439, $p=0.046$ ), and male sex was 1.66 (95\% confidence interval: $1.065-2.573, p=0.025)$, respectively. As life-threatening bleeding events were not observed, prolonged PT-INR might directly or indirectly affect DIC-related mortality caused by rTM treatment.

Conclusion: rTM treatment for DIC was less effective in male patients with PT-INR $\geq 1.67$ and age $\geq 75$ years.

Keywords: Recombinant human soluble thrombomodulin, Disseminated intravascular coagulation, Prothrombin time-international normalized ratio, Antithrombin III, Intensive care unit

\footnotetext{
* Correspondence: yuki0715asai@gmail.com

Pharmacy, National Hospital Organization Mie Chuo Medical Center, 2158-5

Hisaimyojincho, Tsu, Mie 514-1101, Japan
}

(c) The Author(s). 2020 Open Access This article is licensed under a Creative Commons Attribution 4.0 International License, which permits use, sharing, adaptation, distribution and reproduction in any medium or format, as long as you give appropriate credit to the original author(s) and the source, provide a link to the Creative Commons licence, and indicate if changes were made. The images or other third party material in this article are included in the article's Creative Commons licence, unless indicated otherwise in a credit line to the material. If material is not included in the article's Creative Commons licence and your intended use is not permitted by statutory regulation or exceeds the permitted use, you will need to obtain permission directly from the copyright holder. To view a copy of this licence, visit http://creativecommons.org/licenses/by/4.0/ The Creative Commons Public Domain Dedication waiver (http://creativecommons.org/publicdomain/zero/1.0/) applies to the data made available in this article, unless otherwise stated in a credit line to the data. 


\section{Background}

Disseminated intravascular coagulation (DIC) is among the most common emergency conditions and is characterized by organ damage because of microvascular obstruction by excessive thrombin production [1]. Simultaneous administration of platelets and coagulation factors leads to systemic hemorrhage. Because DIC is associated with high mortality, both early diagnosis and appropriate therapy are essential to improve patient outcomes [2].

Thrombomodulin (TM) is a protein that binds with high affinity to thrombin and protein $C$ receptor, thus performing an important role in regulating coagulation [3]. Activated protein C produced following controlled degradation of the thrombin-TM complex inhibits thrombin generation by degrading and inactivating the coagulation factors VIIIa and V [4]. Recombinant human soluble thrombomodulin (rTM), a novel anticoagulant, has been widely used to improve DIC status in Japan [5-7]. Recently, Saito et al. [5] revealed no significant differences in DIC resolution rates following rTM treatment and heparin treatment; they also demonstrated that bleeding events following rTM treatment were lower than following heparin treatment. Although rTM treatment is highly effective and safe according to many studies [5-7], a randomized, double-blind, multinational, multicenter phase 3 study (SCARLET Randomized Clinical Trial) has reported no significant differences in 28-day mortality rate following rTM therapy and that following placebo therapy [8]. Consequently, there is no consensus on the effectiveness of rTM because some factors could affect the research results. Therefore, revealing the factors influencing rTM efficacy may help in demonstrating the effectiveness of rTM by limiting the patients receiving rTM.

The aim of the present study was to determine the factors influencing DIC-related mortality in patients after rTM treatment.

\section{Methods}

\section{Subjects}

This single-center, retrospective case-control study was performed at the National Hospital Organization Mie Chuo Medical Center (Mie, Japan), using electronic medical records. Herein, DIC was evaluated using the diagnostic criteria specified by the Japanese Association for Acute Medicine (JAAM) DIC scoring system (Table 1) [9]. DIC was diagnosed when the JAAM DIC score exceeded 4 points. We selected 251 adult, hospitalized patients treated with rTM from October 2010 to May 2020. Among these patients, 227 patients diagnosed with DIC were enrolled.
Table 1 Diagnostic criteria for DIC by the JAAM scoring system [9]

\begin{tabular}{llll}
\hline & & & Poin \\
\hline SIRS score $[10]$ & Body temperature $\left({ }^{\circ} \mathrm{C}\right)$ & $38 \leqq$ or $\leqq 36$ & \\
& Respiratory rate & $20 / \mathrm{min} \leqq$ & \\
& Heart rate & $90 / \mathrm{min} \leqq$ \\
& WBC $(/ \mu \mathrm{L})$ & $12,000 \leqq$ or $\leqq 4000$ \\
& & positive factor $3 \leqq$ & 1 \\
& $8 \leqq<12$ & 1 \\
$\mathrm{PLT}\left(\times 10^{4} / \mu \mathrm{L}\right)$ & $<8$ & 3 \\
& & $1.2 \leqq$ & 1 \\
$\mathrm{PT}-\mathrm{INR}$ & $10 \leqq<25$ & 1 \\
FDP $(\mu \mathrm{g} / \mathrm{mL})$ & & $25 \leqq$ & 3
\end{tabular}

$\mathrm{DIC}$ is diagnosed when exceeded total of 4 points

FDP fibrinogen degradation products, $P L T$ platelet, PT-INR prothrombin timeinternational normalized ratio, SIRS systemic inflammatory response syndrome, WBC white blood cell

\section{Baseline characteristics}

The primary outcome was 28-day mortality after rTM treatment. We classified patients into survival and death groups based on whether they survived for 28 days. Baseline clinical characteristics and laboratory data that were examined in parallel to rTM treatment (Table 2).

\section{Statistical analysis}

As previous studies reported that the 28-day mortality after rTM treatment was lesser than $40 \%[8,11]$, we expected a minimum 28-day mortality rate of $40 \%$ after rTM treatment. Considering 90\% power for this study and a significance level of 0.05 , sample size was calculated as 182 per group. Continuous variables were compared between the survival and death groups using Student's $t$-test or Mann-Whitney $U$ test. Fisher's exact test was conducted to compare categorical variables between the groups. The overall survival rate was calculated using Kaplan-Meier estimator and compared using the log-rank test. The missing value of PT-INR in the survival $(n=2)$ and death groups $(n=2)$ were replaced by the median values of each group, respectively. Multivariate analysis was conducted using the Coxproportional hazards model. For Cox-proportional hazards model, explanatory factors determined using univariate analysis with $p<0.1$ were used. Furthermore, some factors considered to affect DIC-related mortality including age $\geq 75$ years [12], rTM dose $\geq 380 \mathrm{U} / \mathrm{kg}$ [13], ATIII treatment [11], and diseases with a poor prognosis (sepsis, solid tumors, and trauma) [1] were added as covariates. Moreover, the cutoff value for the extracted continuous variables calculated from receiver operating characteristic (ROC) analysis was used (Fig. 1). Statistical analyses were performed using EZR software (Saitama 
Table 2 Baseline clinical characteristics and laboratory data of patients

\begin{tabular}{|c|c|c|c|}
\hline \multirow[t]{2}{*}{ Factors } & \multirow{2}{*}{$\begin{array}{l}\text { Survival } \\
n=124\end{array}$} & \multirow{2}{*}{$\begin{array}{l}\text { Death } \\
n=103\end{array}$} & \multirow[t]{2}{*}{$p$ value } \\
\hline & & & \\
\hline Sex (Male/Female) & $69 / 55$ & $72 / 31$ & $0.029^{\mathrm{a}}$ \\
\hline Age & $77(68.5-85.5)^{\mathrm{e}}$ & $79(72-87)^{\mathrm{e}}$ & $0.702^{\mathrm{b}}$ \\
\hline Body weight (kg) & $51.3(45.8-60.0)^{\mathrm{e}}$ & $48(42-59)^{e}$ & $0.322^{\mathrm{b}}$ \\
\hline eGFR (mL/min/1.73 m²) & $38.5(16.4-57.3)^{\mathrm{e}}$ & $42.5(22.9-69.1)^{\mathrm{e}}$ & $0.272^{c}$ \\
\hline Proportion of patients with sepsis-induced DIC (\%) & 96 & 93 & $0.283^{\mathrm{a}}$ \\
\hline Proportion of patients with solid tumor-induced DIC (\%) & 1.5 & 4 & $0.411^{\mathrm{a}}$ \\
\hline Proportion of patients with trauma-induced DIC (\%) & 2.5 & 3 & $1.000^{\mathrm{a}}$ \\
\hline SIRS score & $2(1.0-3.0)^{\mathrm{e}}$ & $2(1.0-3.0)^{\mathrm{e}}$ & $0.226^{\mathrm{b}}$ \\
\hline $\mathrm{FDP}(\mu \mathrm{g} / \mathrm{mL})$ & $32.5(19.2-64.8)^{\mathrm{e}}$ & $41.6(20.7-77.1)^{\mathrm{e}}$ & $0.137^{c}$ \\
\hline $\operatorname{PLT}\left(\times 10^{4} / \mu \mathrm{L}\right)$ & $5.6(3.8-7.7)^{\mathrm{e}}$ & $5.5(3.2-7.4)^{\mathrm{e}}$ & $0.688^{c}$ \\
\hline PT-INR & $1.26(1.17-1.44)^{\mathrm{e}}$ & $1.44(1.28-1.72)^{\mathrm{e}}$ & $<0.001^{c}$ \\
\hline Proportion of patients with warfarin treatment (\%) & 2.5 & 1.9 & $1.000^{\mathrm{a}}$ \\
\hline DIC score ${ }^{d}$ & $7(5.8-9.0)^{\mathrm{e}}$ & $7(6.0-9.0)^{\mathrm{e}}$ & $0.365^{\mathrm{b}}$ \\
\hline rTM dose $(\mathrm{U} / \mathrm{kg})$ & $351(246-381)^{\mathrm{e}}$ & $312(223-381)^{\mathrm{e}}$ & $0.508^{\mathrm{b}}$ \\
\hline Number of patients treated with ATIII & 31 & 25 & $1.000^{b}$ \\
\hline Number of patients treated in ICU & 63 & 39 & $0.061^{\mathrm{a}}$ \\
\hline
\end{tabular}

eGFR estimate glomerular filtration rate, SIRS systemic inflammatory response syndrome, FDP fibrinogen degradation products, $P L T$ platelet, $P T$-INR prothrombin time-international normalized ratio, ATIII antithrombin III, ICU intensive care unit

${ }^{a}$ Fisher's exact test. ${ }^{b}$ Student's $t$-test. ' Mann-Whitney $U$ test. ${ }^{d}$ JAAM score. ${ }^{\text {EEach }}$ value represents the median (25-75\% percentile)

Medical Center, Jichi Medical University, Saitama, Japan) [14] with significance established at $p<0.05$.

\section{Results}

The proportion of patients with the subtype of diseases that caused DIC, such as sepsis, solid tumors, and trauma, was shown in Table 2, but the

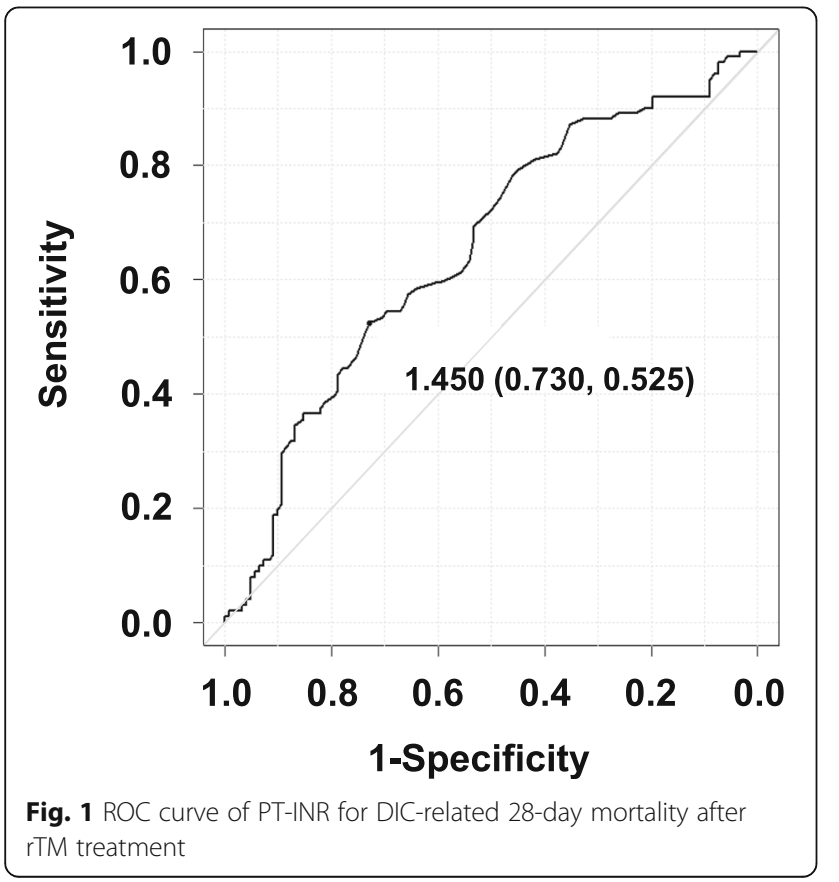

proportion was not statistically different between the survival and death groups. The 28-day mortality rate after rTM treatment was $45.4 \%$ (124/227 patients). Univariate analysis revealed that male sex $(p=0.029)$, treatment in ICU $(p=0.061)$, and PT-INR $(p<0.001)$ are possible factors influencing DIC-related 28-day mortality after rTM treatment (Table 2). The PT-INR cutoff value was 1.45 which corresponds to the results of the ROC analysis (sensitivity: 73\%, specificity: 53\%, area under the curve: 0.65) (Fig. 1). Figure 2 displays Kaplan-Meier curves for 28-day mortality after rTM treatment in patients with PT-INR $<1.67$ and PT-INR $\geq$ 1.67. The adjusted odds ratio for 28-day mortality in patients with PT-INR $\geq 1.67$ was 2.23 (95\% confidence interval: $1.451-3.433, p<0.001)$, age $\geq 75$ years was $1.57(95 \%$ confidence interval: $1.009-2.439, p=0.046)$, and male sex was 1.66 (95\% confidence interval: $1.065-2.573, p=0.025$ ) (Table 3) Life-threatening bleeding events were not observed in the mortality group.

\section{Discussion}

The 28-day mortality rate after rTM treatment was consistent with those reported in previous studies [8, 11]. Although the DIC scores in the survival and death groups were similar, the efficacy of rTM treatment were different. Therefore, we performed Coxproportional hazard analysis to elucidate the influential factors. 


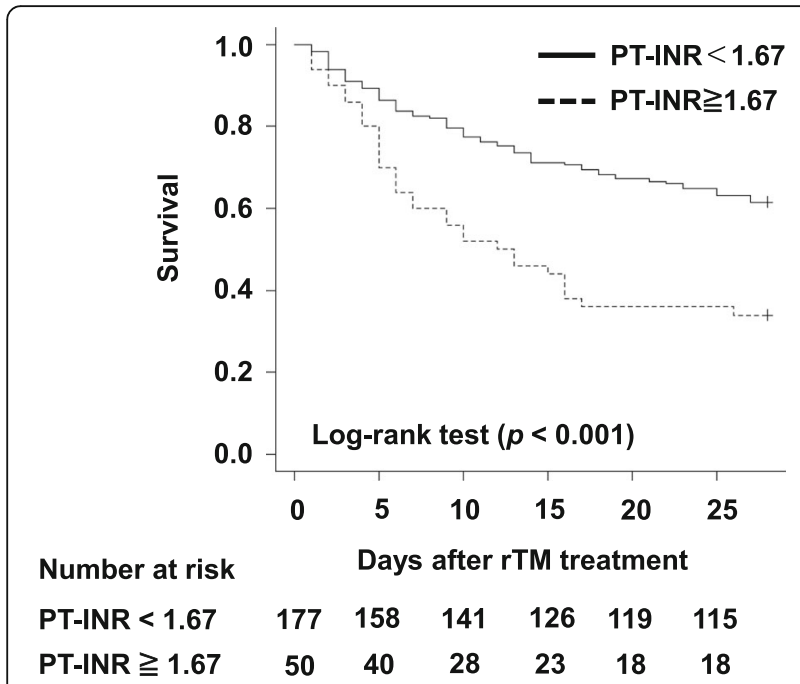

Fig. 2 28-day survival curves after rTM in patients with PT-INR $\geq 1.67$ and PT-INR $<1.67$. The survival rate of patients with PT-INR $<1.67$ was significantly higher than that of patients with $P T-I N R \geq 1.67$ $(p<0.001)$. PT-INR, prothrombin time-international normalized ratio; rTM, recombinant human soluble thrombomodulin

Elderly patients have reportedly higher mortality rates due to DIC [12]. In this study, we confirmed that the mortality rate was higher for patients over 75 years old than those under 75 years old, indicating that elderly patients have a high mortality rate from DIC even after rTM administration.

According to a previous study, effective blood concentration is not reached unless the dose of rTM is $380 \mathrm{U} /$ $\mathrm{kg}$ [13]. Our study showed that the rTM dosage might not be related to efficacy for DIC-related mortality. Further studies are needed to understand the association between blood rTM concentrations and DIC resolution.

Although ROC analysis indicated that the cutoff value of PT-INR was 1.45 (Fig. 1), its clinical relevance is unknown. In the Japanese Ministry of Health and Welfare scoring system, the severity according to PT-INR $<1.25$, $1.25 \leq \mathrm{PT}-\mathrm{INR}<1.67$, and $1.67 \leq \mathrm{PT}$-INR are scored as 0 , 1 , and 2 points, respectively, [2]. Therefore, we selected $\mathrm{PT}$-INR $\geq 1.67$ as the cutoff value. Cox-proportional hazard analysis demonstrated that the 28-day mortality rate in patients with $\mathrm{PT}-\mathrm{INR} \geq 1.67$ was significantly lower than that in patients with PT-INR $<1.67$ (Table 3 and Fig. 2), suggesting that PT-INR $\geq 1.67$ might be a key factor influencing rTM treatment. The major adverse events occurring in patients with DIC who receive rTM are bleeding-related events [15]. Sugawara et al. [15] have suggested that rTM increases the incidence of bleeding-related adverse events, implying that rTM therapy in patients with PT-INR $\geq 1.67$ increases the risk of these events. Conversely, an animal study [16] has shown that rTM does not affect the clotting time. Considering our study results, hemorrhage might not affect
Table 3 Cox proportional hazard analysis of some factors of 28day mortality following rTM treatment

\begin{tabular}{llll}
\hline Factors & Adjusted OR & $\mathbf{9 5 \%} \mathbf{C l}$ & $\boldsymbol{p}$ value \\
\hline Male & 1.66 & $1.065-2.573$ & 0.025 \\
Age $\geqq 75$ & 1.57 & $1.009-2.439$ & 0.046 \\
Sepsis-induced DIC & 0.32 & $0.075-1.369$ & 0.125 \\
Solid tumor-induced DIC & 0.54 & $0.096-3.057$ & 0.487 \\
Trauma-induced DIC & 0.45 & $0.074-2.787$ & 0.393 \\
PT-INR $\geqq 1.67$ & 2.23 & $1.451-3.433$ & $<0.001$ \\
rTM Dose $\geqq 380 ~ U / k g$ & 0.95 & $0.608-1.484$ & 0.820 \\
ATIII co-treatment & 0.95 & $0.598-1.501$ & 0.818 \\
Treatment in ICU & 0.91 & $0.595-1.380$ & 0.645 \\
\hline
\end{tabular}

OR odds ratio, $95 \% \mathrm{Cl} 95 \%$ confidence interval

ATIII antithrombin III, ICU intensive care unit, PT-INR prothrombin timeinternational normalized ratio

the 28-day mortality after rTM treatment. A study has revealed that prolonged PT-INR and FDP correlates with DIC severity [2]. Since both severe and mild cases of DIC status were randomly selected in the SCARLET study, the effectiveness of rTM was not proved conclusively [8], suggesting that the rTM treatment for mild DIC status (PT-INR $\geq 1.67$ ) might be effective. However, the value of FDP was not different between the survival and death groups (Table 1), indicating that severe DIC status and other factors related to PT-INR affected rTM efficacy. Warfarin treatment is known to elevate PT-INR [17]. In the present study, because five subjects (three and two subjects from the survival and death groups, respectively) were treated with warfarin (Table 2), their prolonged PT-INR might be influenced by warfarin treatment. Further studies are needed to understand whether prolonged PT-INR directly or indirectly affects DIC-related mortality.

Although male sex was extracted as a factor influencing DIC-mortality after rTM treatment (Table 3), the phenomenon of sex differences has not been reported. Estrogen, a potent steroid hormone present in high levels in females, may have great benefits in antiinflammation and vascular protection [18]. It is speculated that differences in sex hormones can affect the reactivity of rTM, but further investigation is needed.

Our study design has several limitations. First is the lack of statistical power given the small sample size. Second, because this was a retrospective study, DIC resolution rate could not be evaluated owing to the lack of corresponding information in electronic medical records. Third, non-life-threatening bleeding events, such as gastrointestinal bleeding or intracerebral bleeding, could not be confirmed. Fourth, the underlying diseases in patients were often unknown due to the lack of corresponding information in electronic medical records. 
Fifth, since the sequential organ failure assessment score was measured only in ICU patients at the Mie Chuo Medical Center from 2019, organ damage was not estimated in the present study.

\section{Conclusions}

This study reveals that PT-INR $\geq 1.67$, age $\geq 75$ years, and male sex may be a factor associated with DICrelated 28-day mortality after rTM treatment. Although the mechanisms underlying the increased mortality rate in patients with PT-INR $\geq 1.67$ remain unknown, we proposed that rTM treatment may be less effective in such patients.

\section{Abbreviations \\ DIC: Disseminated intravascular coagulation; FDP: Fibrinogen degradation products; ICU: Intensive care unit; JAMA: Japanese association for acute medicine; PT-INR: Prothrombin time-international normalized ratio; ROC: Receiver operating characteristic; rTM: Recombinant human soluble thrombomodulin; TM: Thrombomodulin}

\section{Acknowledgments}

Not applicable.

\section{Authors' contributions}

All authors edited the manuscript and approved the final version

\section{Funding}

Not applicable.

\section{Availability of data and materials}

All the data generated or analyzed in this study are included in the published article.

\section{Ethics approval and consent to participate}

The protocol of the present study was approved by the ethics committee of the National Hospital Organization Mie Chuo Medical Center. Because this study was a retrospective case-control study, consent was obtained from each patient using an opt-out document posted on the website of the Mie Central Medical Center.

\section{Consent for publication}

Not applicable.

\section{Competing interests}

The authors declare that they have no competing interests.

Received: 9 September 2020 Accepted: 26 November 2020 Published online: 02 December 2020

\section{References}

1. Levi M, Ten-Cate H. Disseminated intravascular coagulation. N Engl J Med. 1999;341:582-92.

2. Wada H, Gabazza-Esteban C, Asakura H, Koike K, Okamoto K, Maruyama I, Shiku H, Nobori T. Comparison of diagnostic criteria for disseminated intravascular coagulation (DIC): diagnostic criteria of the International Society of Thrombosis and Hemostasis and of the Japanese Ministry of Health and Welfare for overt DIC. Am J Hematol. 2003;74:17-22.

3. Weiler H. Regulation of inflammation by the protein $\mathrm{C}$ system. Crit Care Med. 2010;38:S18-25.

4. Naomi L, Esmon-Whyte G, Esmon-Charles T. Isolation of a membrane-bound cofactor for thrombin-catalyzed activation of protein C. J Biol Chem. 1982; 257:859-64.

5. Saito H, Maruyama I, Shimazaki S, Yamamoto Y, Aikawa N, Ohno R, Hirayama A, Matsuda T, Asakura H, Nakashima M, Aoki N. Efficacy and safety of recombinant human soluble Thrombomodulin (ART-123) in disseminated intravascular coagulation: results of a phase III, randomized, Double-Blind Clinical Trial. J Thromb Haemost. 2007:5:31-41.

6. Itoh S, Shirabe K, Kohnoe S, Sadanaga N, Kajiyama K, Yamagata M, Anai H, Harimoto N, Ikegami T, Yoshizumi T, Maehara Y. Impact of recombinant human soluble Thrombomodulin for disseminated intravascular coagulation. Anticancer Res. 2016;36:2493-6.

7. Yoshihiro S, Sakuraya M, Hayakawa M, Ono K, Hirata A, Takaba A, Kawamura $\mathrm{N}$, Tsutsui T, Yoshida K, Hashimoto Y. Recombinant human-soluble Thrombomodulin contributes to reduced mortality in Sepsis patients with severe respiratory failure: a retrospective observational study using a multicenter dataset. Shock. 2019;51:174-9.

8. Vincent JL, Francois B, Zabolotskikh I, Kumar-Daga M, Lascarrou J, KirovMikhail Y, Pettilä V, Wittebole X, Meziani F, Mercier E, Lobo-Suzana M, BariePhilip S, Crowther M, Esmon-Charles T, Fareed J, Gando S, Gorelick-Kenneth J, Levi M, Jean-Paul M, Opal-Steveb M, Parrillo J, Russell-James A, Saito H, Tsuruta K, Sakai T, Fineberg D, SCARLET Trial Group. Effect of a Recombinant Human Soluble Thrombomodulin on Mortality in Patients With SepsisAssociated Coagulopathy: The SCARLET Randomized Clinical Trial. JAMA. 2019;321:1993-2002

9. Gando S, IbavT EY, Ohtomo Y, Okamoto K, Koseki K, Mayumi T, Murata A, Ikeda T, Ishikura H, Ueyama M, Ogura H, Kushimoto S, Saitoh D, Endo S, Shimazaki S, Japanese Association for Acute Medicine Disseminated Intravascular Coagulation (JAAM DIC) Study Group. A multicenter, prospective validation of disseminated intravascular coagulation diagnostic criteria for critically ill patients: comparing current criteria. Crit Care Med. 2006:34:625-31.

10. Kaukonen K, Bailey M, Pilcher D, Jamie-Cooper D, Bellomo R. Systemic inflammatory response syndrome criteria in defining severe Sepsis. N Engl J Med. 2015;372:1629-38.

11. Sawano H, Shigemitsu K, Yoshinaga Y, Tsuruoka A, Natsukawa T, Hayashi Y, Kai T. Combined therapy with antithrombin and recombinant human soluble thrombomodulin in patients with severe sepsis and disseminated intravascular coagulation. JJAAM. 2013;24:119-31.

12. Banno S, Nitta M, Kikuchi M, Takada K, Mitomo Y, Niimi N, Yamamoto T. Disseminated intravascular coagulation (DIC) and pre-DIC due to severe infection in the elderly. Nihon Ronen Igakkai Zasshi. 1994;31:747-51.

13. Hayakawa M, Kushimoto S, Watanabe E, Goto K, Suzuki Y, Kotani T, Kiguchi T, Yatabe T, Tagawa J, Komatsu F, Gando S. Pharmacokinetics of recombinant human soluble thrombomodulin in disseminated intravascular coagulation patients with acute renal dysfunction. Thromb Haemost. 2017; 117:851-9.

14. Kanda Y. Investigation of the freely available easy-to-use software 'EZR' for medical statistics. Bone Marrow Transplant. 2013;48:452-8.

15. Sugawara J, Suenaga K, Hoshiai T, Sato T, Nishigori H, Nagase S, Yaegashi N. Efficacy of recombinant human soluble Thrombomodulin in severe postpartum hemorrhage with disseminated intravascular coagulation. Clin Appl Thromb Hemost. 2013;19:557-61.

16. Mohri M, Gonda Y, Oka M, Aoki Y, Gomi K, Kiyota T, Sugihara T, Yamamoto $\mathrm{S}$, Ishida T, Maruyama I. The antithrombotic effects of recombinant human soluble Thrombomodulin (rhsTM) on tissue factor-induced disseminated intravascular coagulation in crab-eating monkeys (Macaca Fascicularis). Blood Coagul Fibrinolysis. 1997;8:274-83.

17. Lutomski DM, Djuric PE, Draeger RW. Warfarin therapy. The effect of heparin on prothrombin times. Arch Intern Med. 1987;147:432-3.

18. Knowlton AA, Lee AR. Estrogen and the cardiovascular system. Pharmacol Ther. 2012;135:54-70.

\section{Publisher's Note}

Springer Nature remains neutral with regard to jurisdictional claims in published maps and institutional affiliations. 